\title{
Use of DNA barcoding in the assignment of commercially valuable fish species from Romania
}

\author{
Gina-Oana Popa ${ }^{\mathrm{a}, 1}$, Andreea Dudu ${ }^{\mathrm{a}, 1}$, Doru Bănăduc ${ }^{2}$, Angela Curtean-Bănăduc ${ }^{2}$, Teodora Barbălată ${ }^{1}$, \\ Alexandru Burcea ${ }^{1}$, Iulia Elena (Gune) Florescu ${ }^{1}$, Sergiu Emil Georgescu ${ }^{1,{ }^{*}}$ and Marieta Costache ${ }^{1}$ \\ ${ }^{1}$ Department of Biochemistry and Molecular Biology, Faculty of Biology, University of Bucharest, Bucharest 050095, Romania \\ 2 Applied Ecology Research Centre, Faculty of Sciences, "Lucian Blaga" University of Sibiu, Sibiu 550012, Romania
}

Received 29 November 2016 / Accepted 1 May 2017

\begin{abstract}
DNA barcoding is a molecular technique frequently used either for biodiversity monitoring and fish conservation or in the identification of the species of origin for raw and processed food from restaurants or fish markets. The most important aspect of this technique is that it works for all stages of life and can be used to distinguish between closely related taxa. Also, the technique has been used to unmask attempts of frauds in fish markets where more desirable and expensive fish are sometimes substituted with lower valued species. Our study aims to test the utility of the COI barcoding gene in the correct identification of several economically and ecologically valuable fish species, and interspecies hybrids, from Romanian wild fauna, aquaculture and fish markets. By combining the $122 \mathrm{COI}$ sequences generated here with additional barcodes downloaded from GenBank and BOLD we screened several members of Acipenseriformes and Salmoniformes. While COI was able to correctly classify the majority of Salmoniformes, the identification process for Acipenseriformes proved more difficult, especially in the case of hybrids. Although the results show that DNA barcodes present a low degree of interspecies variation making classification possible only at the genus level, this technique is still relatively cheap, fast, and useful in the identification of incorrectly labelled market products.
\end{abstract}

Keywords: DNA barcoding / Salmoniformes / Acipenseriformes / Wild fauna / Aquaculture / Fish market

\section{Introduction}

DNA barcoding is a molecular technique that is commonly used for biodiversity monitoring and fish conservation (Hebert et al., 2003; Holmes et al., 2009), as well as in the species-level identification of raw and processed food from restaurants or fish markets (Filonzi et al., 2010; Cline, 2012). DNA barcoding is a powerful tool because it works for all stages of life and it can be used to distinguish between closely related taxa (Stoeckle et al., 2004). Subunit I of the cytochrome oxidase (COI) gene has been used in numerous studies with high degree of success (Galimberti et al., 2012). For instance, COI has been successfully used to identify freshwater fish species with over a 93\% success rate (Ward et al., 2009). There is great interest in using COI barcoding for aquatic species as indicated by the numerous scientific articles on this topic (Taylor and Harris, 2012). There are also efforts to identify shorter DNA fragments for use as barcodes, called mini-barcodes, for situations where

\footnotetext{
${ }^{\mathrm{a}}$ These authors contributed equally to this work.

* Corresponding author: georgescu_se@yahoo.com
}

obtaining a fragment longer than $400 \mathrm{bp}$ is not possible (Meusnier et al., 2008; Dubey et al., 2011; Little, 2014; Shokralla et al., 2015). The barcoding technique alone is not suitable for the detection of hybrids for which both nuclear and mitochondrial markers should be assessed. Instead, DNA barcoding can be used to infer the maternal origin of hybrids.

Our study aims to test the utility of the COI barcoding gene and the public databases to accurately identify several economically and ecologically valuable fish species and interspecies hybrids from Romanian wild fauna, aquaculture and fish markets, to determine if COI can be used to identify the maternal lineage of known hybrids and to determine if cultured fishes and those sold in fish markets are correctly identified and labelled.

The issue of mislabelling fish or fish-derived products is a serious one, as there are laws that mandate correct product identification, regardless of its provenience [Council Regulation (EC) No. 1379/2013, http://eur-lex.europa.eu]. However, studies show that up to $30 \%$ of fish products are mislabelled in fish markets and restaurants with the problem being particularly acute in the latter (Pardo et al., 2016). For instance, Ludwig et al. (2015) showed in an analysis of 27 
caviar samples from Romania and Bulgaria, that only ten of them were correctly labelled, while the remaining samples were from Cyclopterus lumpus, a less economically valuable fish species whose roe are often used as a substitute for caviar.

Romania's fisheries production has been in decline, from a harvest of 270000 tons in 1986 to 16238 tons in 2002 (www.fao.org). The most common species used in aquaculture in Romania are the common carp (Cyprinus carpio), the silver crucian carp (Carassius auratus gibelio), the rainbow trout (Oncorhynchus mykiss), and the brown trout (Salmo trutta fario). In the last two decades, sturgeon rearing has become more widespread in Romania with the most popular species being the stellate sturgeon (Acipenser stellatus), Russian sturgeon (Acipenser gueldenstaedtii), beluga sturgeon (Huso huso), and the sterlet (Acipenser ruthenus) (Smederevac-Lalić et al., 2011). Exotic species such as Acipenser baerii and sturgeon hybrids such as: bester

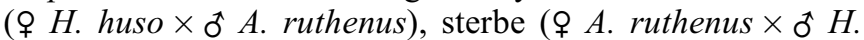
huso) and best beluga [o (H. huso $\times \circlearrowleft$ A ruthenus $) \times \delta H$. huso] are also farmed (Costache et al., 2012; Dudu et al., 2015). A more recent report states that in 2013 cyprinids made up more than $80 \%$ of fish production globally, while trout was only $11 \%$, and sturgeon, along with pike-perch and perch, made up only $2 \%$ (www.eurofish.dk).

Sturgeons are listed in the CITES Appendices (Convention on International Trade in Endangered Species of Wild Fauna and Flora), due to habitat destruction, river regulation and overexploitation (Raymakers, 2007). Sturgeons' protected status as endangered has increased the need for aquaculture farming in order to satisfy the demand for caviar and other sturgeon derived products. To meet the growing demand, fish farms have introduced sturgeon hybrids in their aquaculture programs in order to take advantage of the rapid growth rate and high-quality caviar. This is the case for the

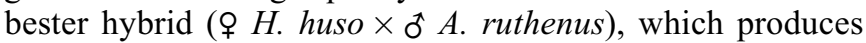
high-quality caviar at a younger age compared to beluga sturgeon (Dudu et al., 2015). Historically, six sturgeon species were native to the Danube River. However, due to the Iron Gate Dams, only four species now populate the Lower section of the river (Paraschiv et al., 2006). The sturgeons found in the Lower Danube are the beluga sturgeon, Russian sturgeon, stellate sturgeon and sterlet (Bacalbasa-Dobrovici, 1997; www.danube-sturgeons.org).

Members of the Salmonidae family that populate Romanian waters are of great ecological and economical value such as the brown trout ( $S$. trutta fario), brook trout (Salvelinus fontinalis), grayling (Thymallus thymallus) and the huchen (Hucho hucho). Most native species are found in mountainous streams with the non-native rainbow trout (O. mykiss) being predominantly raised in fish farms (Dudu et al., 2011a; Georgescu et al., 2011).

The IUCN (International Union for Conservation of Nature) status of these species is as follows: critically endangered for A. stellatus, A. gueldenstaedtii, H. huso; endangered for $A$. baerii and $H$. hucho; vulnerable for $A$. ruthenus; least concern for $S$. trutta and T. thymallus, while the statuses of $O$. mykiss and $S$. fontinalis have yet to be assessed (Gessner et al., 2010).

\section{Materials and methods}

\subsection{Sampling and DNA extraction}

Samples used in this study were either wild caught or collected from participating fish farms throughout Romania. The wild individuals came from several Romanian rivers: Porumbacu, Avrig, Topolog, Cerna and the Danube river, while the fish farms were located in the following counties: Tulcea, Vâlcea, Gorj, Caras-Severin, Cluj-Napoca, Bistrița, Olt and Călărași (Supplementary Material 1). The fish market samples came from three supermarkets from Bucharest and two fish farms from Tulcea County.

We processed 64 samples from the family Salmonidae and 58 from the family Acipenseridae (Fig. 1), morphologically identified or using the product's market label. Tissue samples taken were either fin clips or muscle tissue. DNA was extracted from each tissue using a Chelex-resin based protocol (Estoup et al., 1996), while the quality and quantity of the DNA were assessed by using NanoDrop 8000 (Thermo Scientific).

\subsection{DNA Amplification and sequencing}

DNA amplification of a $5^{\prime}$ fragment of the cytochrome oxidase subunit 1 (COI) gene was done using the standard fish DNA barcoding primers, FishF 1: 5'TCAACCAACCACAAA GACATTGGCAC3'/Fish R1: 5'TAGACTTCTGGGTGGC CGAAGAATCA3' (Ward et al., 2005). However, in samples that failed to amplify we used the following primers which were designed using the Primer3 software (Untergasser et al., 2012): StrSfo F: 5'TCCACCGCTTAAACTCTCAG3'/StrSfo R: 5'CCGGGTCAAAGAAAGTGGTA3', ThyF: 5'TCCACC GCTTAAACACTCAG3'/ThyR: 5'CTGGGTCAAAGAAAG TGGTA3' and Stur F: 5'GAAGGGGACTTTAACCTCTG3'/ Stur R: 5'TAGGCCCGTGTGTCTACGTCC3'. The PCR amplifications were performed in a $25 \mu \mathrm{l}$ final reaction volume containing: $50 \mathrm{ng}$ of DNA template, $1 \times$ PCR buffer (Applied Biosystems), $1.5 \mathrm{mM} \mathrm{MgCl} 2$ (Applied Biosystems), $0.4 \mathrm{mM}$ of each dNTP (Applied Biosystems), $0.4 \mu \mathrm{M}$ of $\mathrm{F}$ primer, $0.4 \mu \mathrm{M}$ of $\mathrm{R}$ primer, $1 \mathrm{U}$ of AmpliTaq Gold Polymerase (Applied Biosystems). The PCR reaction conditions were: $95^{\circ} \mathrm{C}$ for $10 \mathrm{~min}, 35$ cycles of $95^{\circ} \mathrm{C}$ for $30 \mathrm{~s}$, $54{ }^{\circ} \mathrm{C}$ for $30 \mathrm{~s}$, and $72^{\circ} \mathrm{C}$ for $60 \mathrm{~s}$, followed by a final extension of $72{ }^{\circ} \mathrm{C}$ for $10 \mathrm{~min}$ and the amplifications were performed on a Verity Thermal Cycler (Applied Biosystems). The resulting PCR products were electrophoretically assessed for quality, and purified using Wizard SV Gel and PCR Clean-Up System (Promega). Separate forward and reverse strand sequencing amplification was done using BigDye Terminator v3.1 kit (Applied Biosystems). The resulting products were purified using the BigDye XTerminator Purification Kit (Applied Biosystems), followed by sequencing on the ABI Prism 3130 DNA Genetic Analyzer (Applied Biosystems) automatic platform.

\subsection{Genetic diversity and phylogenetic analysis}

COI sequences were edited using BioEdit Sequence Alignment Editor (Hall, 1999). To identify the sequences, we used the following steps proposed by Jo et al. (2014): 


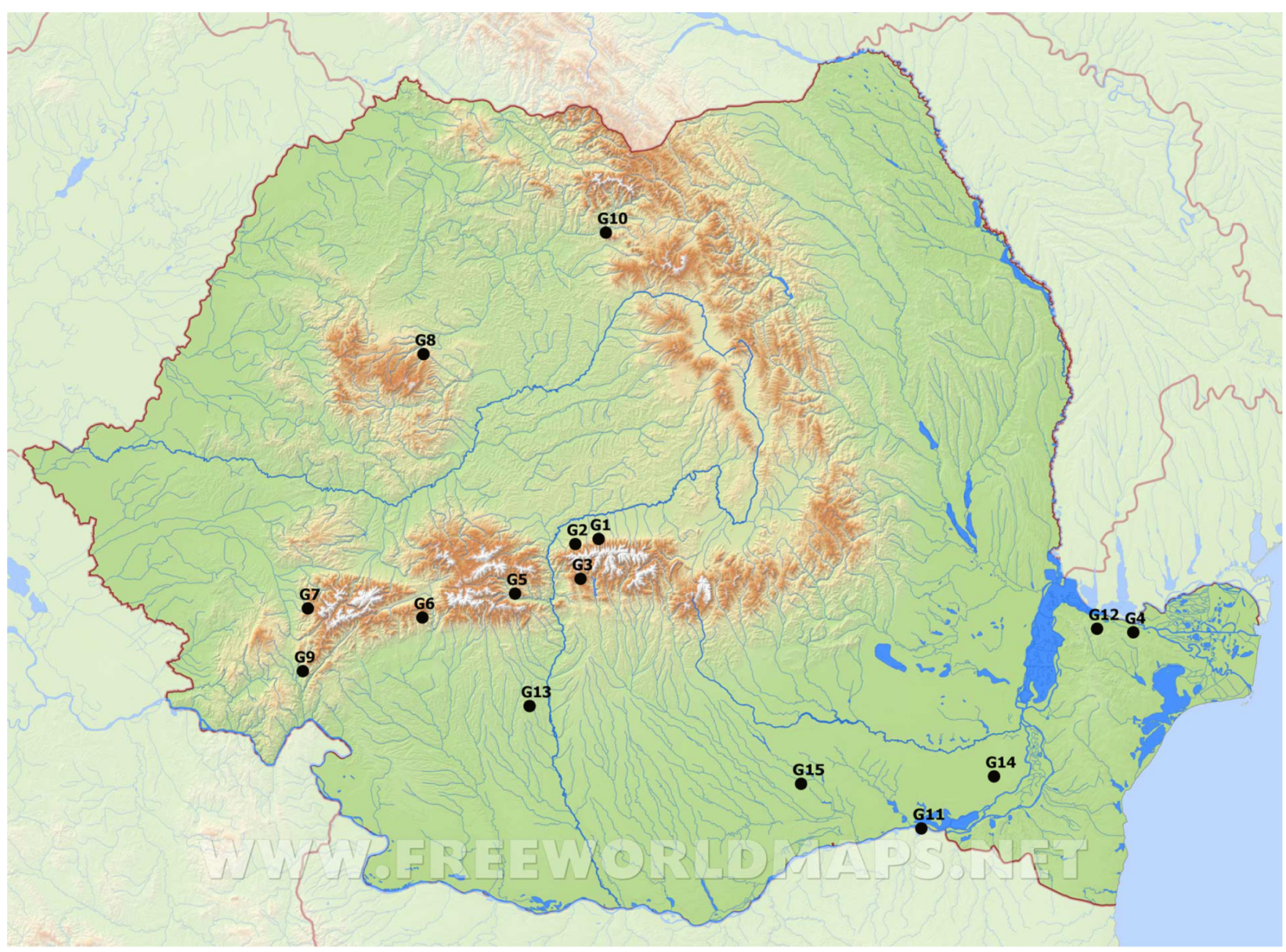

Fig. 1. Map of sampling sites for the 122 specimens collected from Romania (rivers and fish farms) and Romanian fish market. Each group (G) represents the specimens presented in Supplementary Material 1 (http://www.freeworldmaps.net/europe/romania/romania-hd-map.jpg).

(1) search the available online database for a $\geq 98 \%$ match with a known species and (2) construct a phylogenetic tree in order to observe the clustering of our sequences and known species. These authors propose an identification score of $\geq 98 \%$ to classify a species, while a score of $<98 \%$ indicates a higher classification level (genus, family, etc.). The topology of the phylogenetic tree is taken into consideration when interpreting the identification scores. We used Web BLAST (Basic Local Alignment Search Tool) on GenBank (Benson et al., 2013) with the default settings, in order to identify the nearest matching sequences, the Ident and $\mathrm{E}$ (xpect) values. Additionally, we used the Identification option on BOLD (Barcode of Life Data Systems; Ratnasingham and Hebert, 2013) to obtain a list of sequences with the highest similarity. Furthermore, we downloaded the nearest matching sequences from our searches on BOLD and GenBank (Supplementary Material 2) in order to conduct a phylogenetic analysis. For this purpose, all the sequences were aligned and trimmed to $424 \mathrm{bp}$. The final dataset was comprised of 234 sequences: 122 generated here and 112 retrieved from the online databases. The sequences highlighted in grey in Supplemen tary Material 1 were from individuals for which taxonomic classification, based on morphology, was conducted in the field by ichthyologists. We consider these sequences as reference barcodes for the respective species. Sequences were aligned using MAFFT (www.mafft.cbrc.jp/alignment/server; Katoh and Standley, 2013). The best fitting molecular substitution model was assessed using jModelTest2 (Guindon and Gascuel, 2003; Darriba et al., 2012) on CIPRES Science Gateway (www.phylo.org; Miller et al., 2010) with the default settings, while the phylogenetic tree construction was conducted using MEGA6 (Tamura et al., 2013). The trees were visualized with FigTree v1.4 (www. tree.bio.ed.ac.uk/software/figtree). The outgroups used here were Plecoglossus altivelis for salmonids (an Osmeridae family representative closely related to Salmoniformes) and Polyodon spathula for acipenserids (a Polyodontidae family representative belonging to the order Accipenseriformes). The robustness of the phylogenetic relationships was assessed using 1000 replicate bootstraps and the two Maximum Likelihood (ML) trees were constructed using the Tamura3 parameter model (Tamura, 1992), chosen based on the Akaike criterion. Additionally, we used the adegenet $\mathrm{R}$ package (along with its dependencies) (Jombart and Ahmed, 2011) for determining and plotting the genetic distances under the K2P model (Kimura, 1980). 


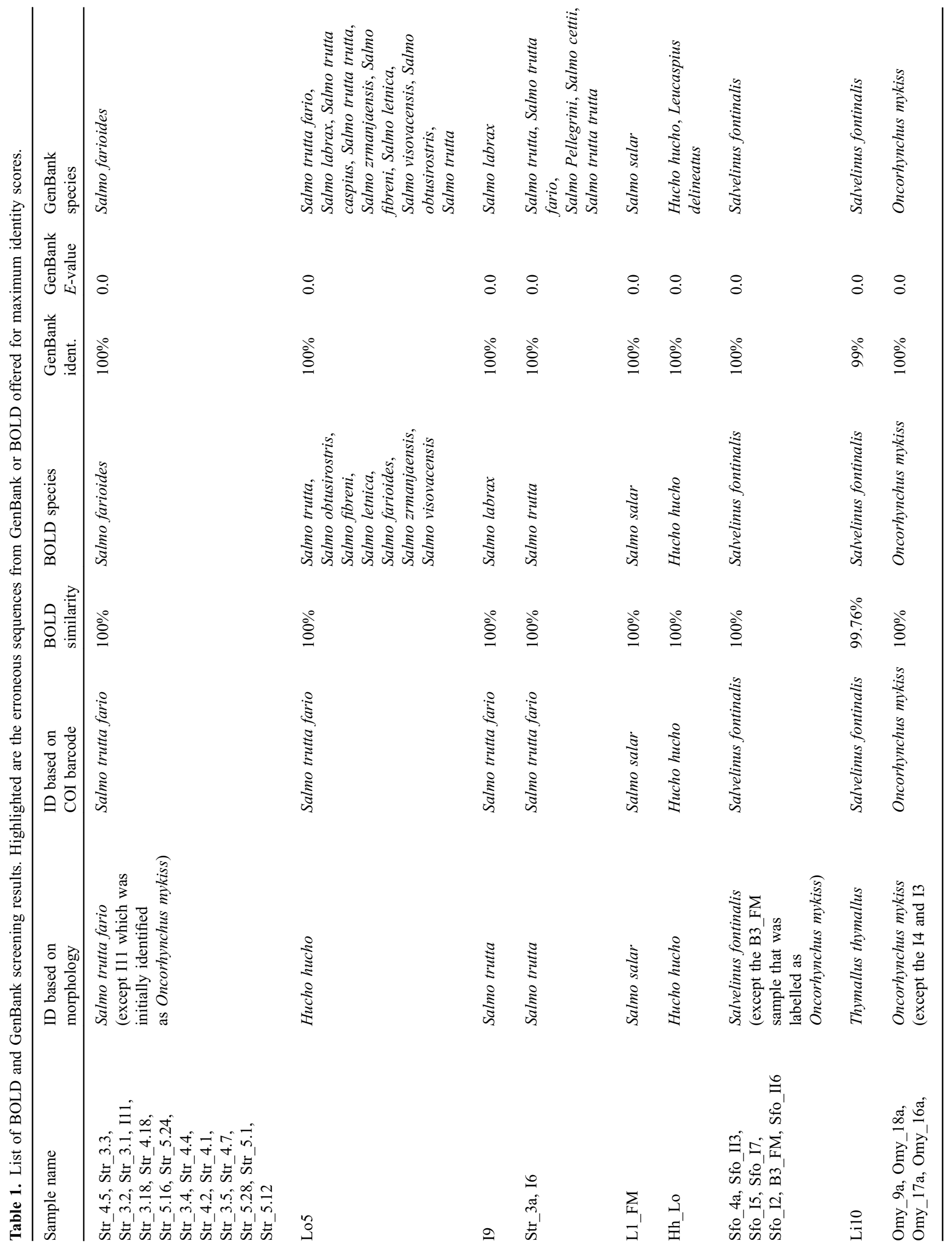




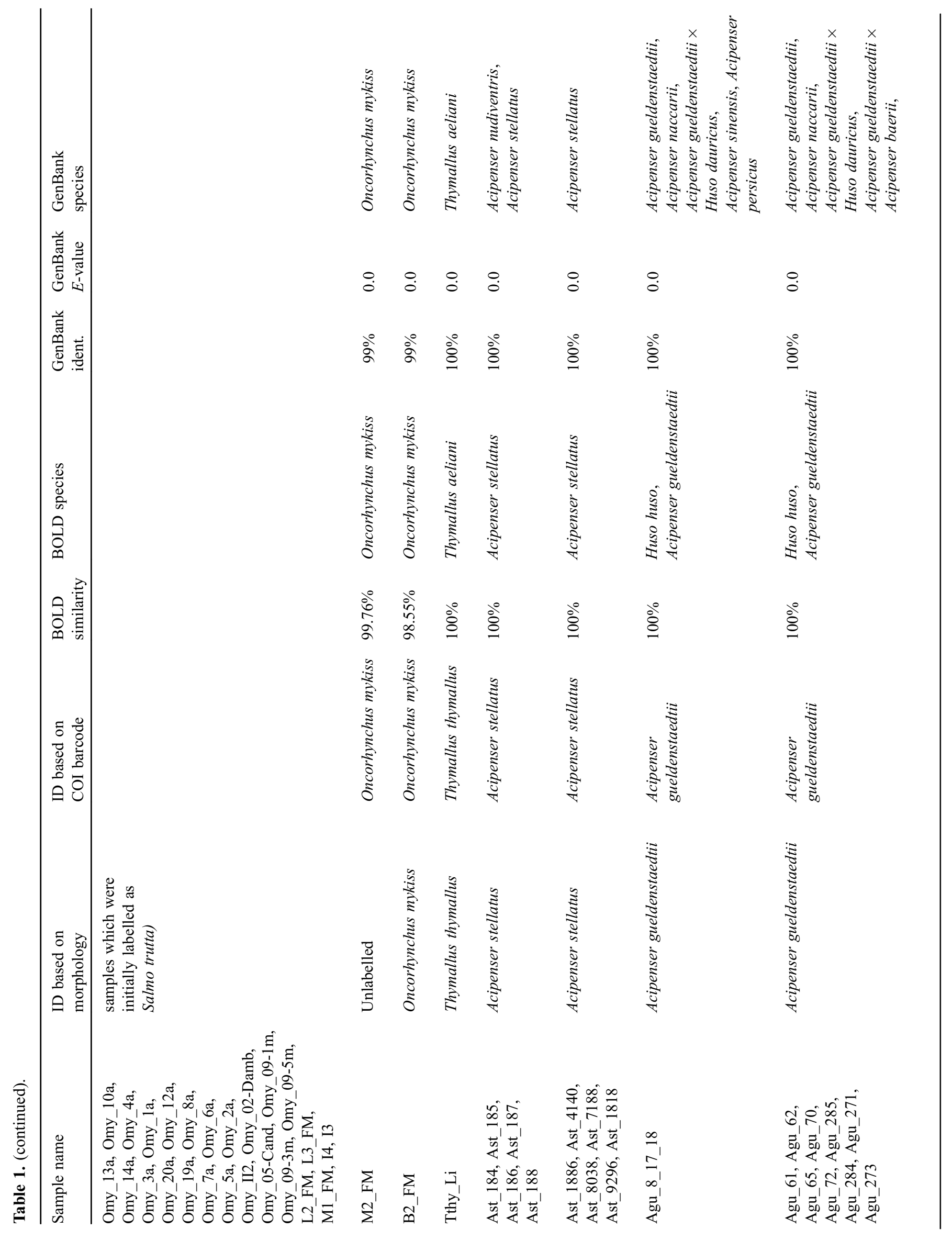




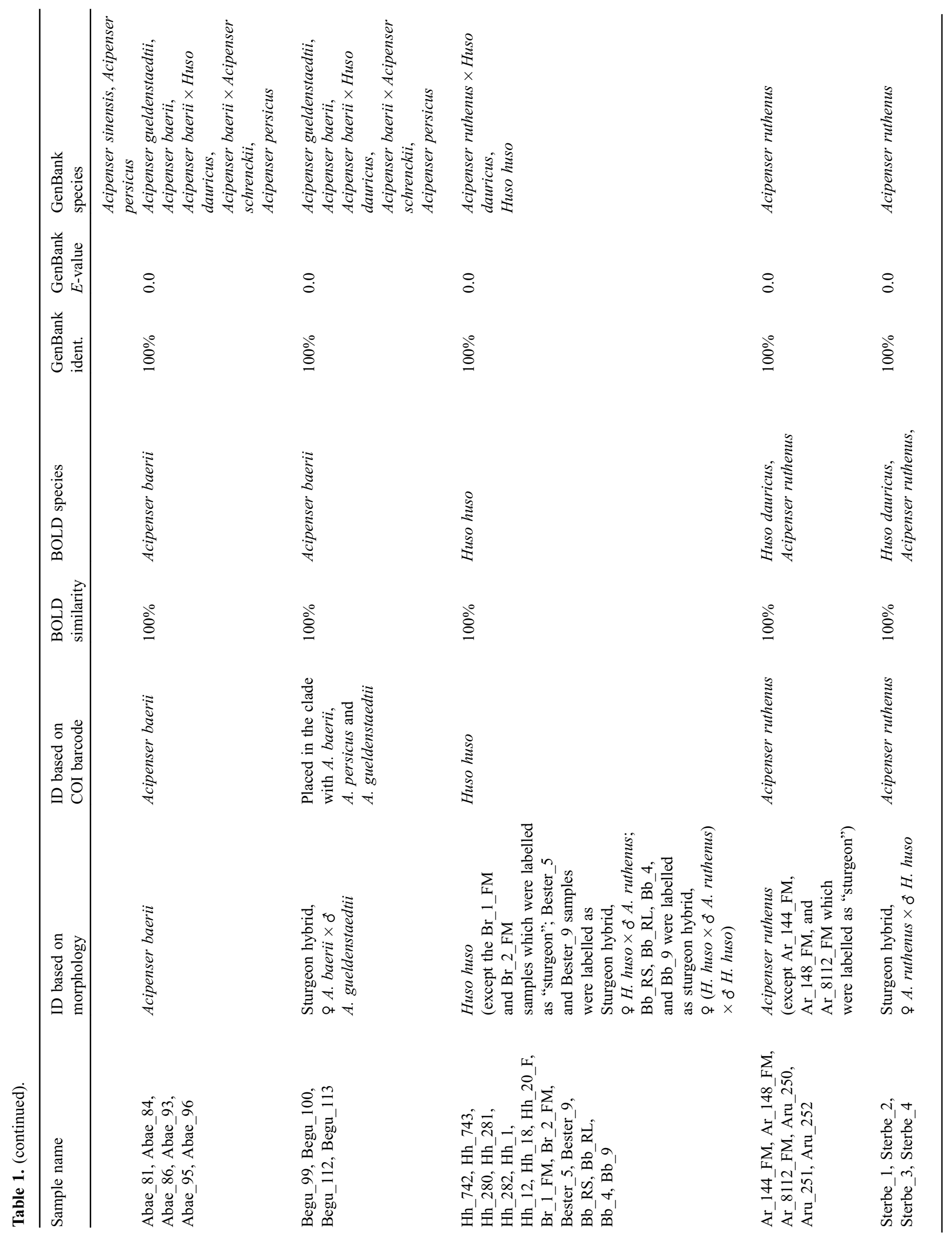




\section{Results}

The majority of the investigated samples was successfully identified after querying against GenBank and BOLD, a result supported by the phylogenetic analysis. However, we observed several erroneous identifications from the online querying, suggesting that both BOLD and GenBank contain several miss-identified samples (Table 1).

\subsection{Species identification through DNA barcoding in salmonids}

All individuals from the Porumbacu, Avrig and Topolog rivers, that were initially morphologically identified as $S$. trutta fario were classified as Salmo farioides by both BOLD and GenBank databases. Interestingly, one individual, initially identified as $O$. mykiss, obtained from a fish farm (CarașSeverin), was also classified as $S$. farioides based on COI.

In another case an individual that had been morphologically identified as $H$. hucho, was classified as Salmo spp. based on COI (Table 1). A different sample from the same fish farm was presented as $H$. hucho with both BOLD and GenBank agreeing on identification (Table 1).

Furthermore, for one sample morphologically identified as S. trutta, both databases showed it to be Black Sea salmon (Salmo labrax, Pallas, 1814) (Table 1). Two samples coming from two different fish farms (Cluj-Napoca and Gorj Counties) were both identified as $S$. trutta, by BOLD and GenBank with a $100 \%$ similarity and identity score, although GenBank has given various other species from the genus Salmo (Table 1). All samples coming from the fish farms that were morphologically identified as $S$. fontinalis were assigned by correctly. This was also true for one wild sample from Cerna River that was identified as a T. thymallus with a score of $99 \%$. However the identification of one fish farm sample labelled as T. thymallus was identified by both GenBank and BOLD as $T$. aeliani a synonym of $T$. thymallus (EUNIS Species Database, http://eunis.eea.europa.eu/species/12979) (Table 1). Samples coming from two different fish farms were morphologically identified as $S$. trutta, but had a maxim score in BOLD and GenBank as $S$. fontinalis (Table 1). All the samples from a fish farm (Tulcea County) morphologically identified as O. mykiss had maxim scores in both databases (GenBank and BOLD) that agreed.

Concerning the fish market samples, the results were mixed with some products not listing species. A sample of smoked fish was identified as $S$. salar, as the product's label stated; however, eight other samples were classified as $O$. mykiss with scores ranging from 98.5 to $100 \%$, but only two of these had labels indicating species (Table 1). Finally, one sample was identified as $S$. fontinalis and it was, along with another mislabelled sample, sold by the marketer as wild $S$. trutta (Table 1).

\subsection{Species identification through DNA barcoding in acipenserids}

The species names for the pure acipenserids based on morphology were in concordance with the results from the database query. For several samples, both BOLD and GenBank gave more than one species name with maximum similarity or identity score. The A. stellatus samples coming from the fish farm (Tulcea County) and from the Danube River were identified as A. stellatus, based on both morphology and our database queries morphology except that GenBank gave a $100 \%$ Identity score for $A$. nudiventris as well. For the samples of $A$. baerii, $H$. huso and several hybrids, namely $H$. huso $\times A$. ruthenus, $H$. huso $\times$ bester and $A$. baerii $\times A$. gueldenstaedtii, BOLD queries resulted in $100 \%$ similarity per species with one result, while GenBank gave more than three matching results, all with $100 \%$ Identity scores. The BOLD classification for the samples above was in concordance with morphological assessments, while the hybrids were successfully barcoded as their maternal genitor species. Thus, begu samples were classified as A. baerii, and bester and best beluga as H. huso. For the best beluga and bester hybrids GenBank showed a $100 \%$ Identity with a hybrid sample of A. ruthenus $\times$ Huso dauricus, while for the begu hybrids, GenBank showed $100 \%$ Identity for two other sturgeon hybrids $A$. baerii $\times H$. dauricus and $A$. baerii $\times A$. schrenckii.

All the $A$. gueldenstaedtii samples were given a maximum similarity score for both $H$. huso and A. gueldenstaedtii, while the $A$. ruthenus samples had a maximum similarity score for both $H$. dauricus and $A$. ruthenus. Concerning the fish market samples, two samples were identified as either $H$. huso or $A$. ruthenus $\times H$. dauricus (Table 1). This is also the case for the $H$. huso, bester, and best beluga from the fish farms. Several fish market samples were identified as either $H$. dauricus or $A$. ruthenus, which is also the case for the $A$. ruthenus samples we had from the fish farm (Table 1).

\subsection{Phylogenetic analysis in salmonids and acipenserids}

The phylogenetic trees illustrating the clustering within Salmoniformes and Acipenseriformes orders are presented in Figure 2 and Supplementary Material 5.

Within the Salmoniformes two different clusters were highlighted: the one that groups all the Thymallus sequences, and the one that groups all the sequences from the genus Salmo, Salvelinus, Oncorhynchus, and Hucho. The Salmo cluster grouped together the sequences representing $S$. trutta fario, $S$. trutta trutta, $S$. labrax, $S$. visovacensis, $S$. letnica, $S$. fibreni, S. farioides, and S. obtusirostris along with our sequences obtained from individuals that were morphologically identified as S. trutta fario, O. mykiss and H. hucho. The phylogenetic analysis confirms the previous database query results and classified one sample, initially labelled as $H$. hucho, as a Salmo spp., while one sample initially labelled as O. mykiss is, in fact, a Salmo spp. The analysis did not clarify the identity of the samples labelled as S. trutta fario, which had received maximum similarity and identity scores as $S$. farioides, since the tree topology shows that all Salmo sequences, except the different clade formed out of $S$. salar, are grouped without any clear boundary.

One fish market sample was grouped in the $S$. salar cluster, this being the species specified on the product label. The phylogenetic analysis grouped together seven sequences obtained in the laboratory into the $S$. fontinalis clade and 30 wild and fish market samples were grouped in the same 

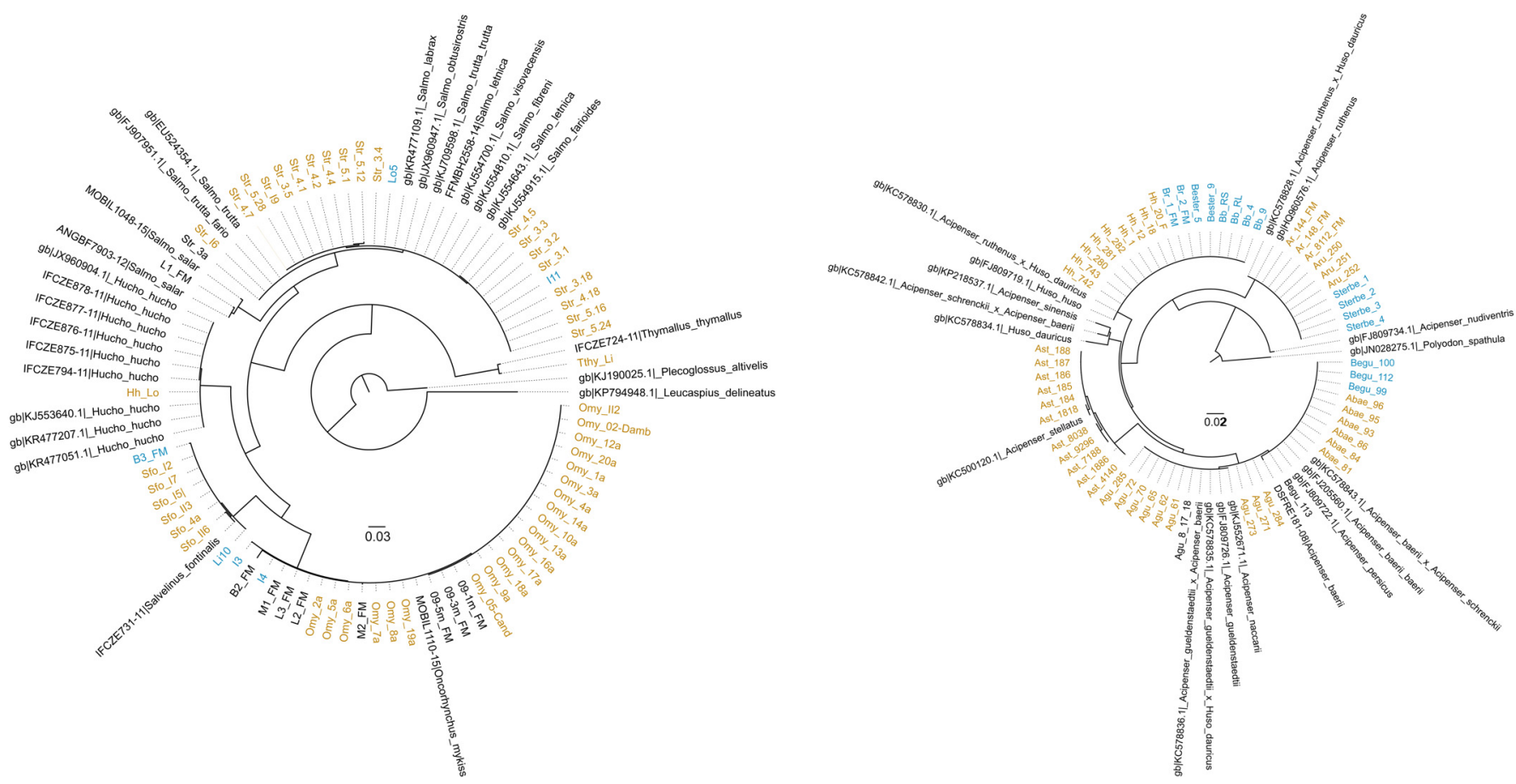

Fig. 2. The phylogenetic trees was inferred by using the Maximum Likelihood (ML) methods (a) for salmonids and (b) for acipenserids based on the Tamura 3-parameter model. For the ML analysis, the tree with the highest log likelihood is shown. The trees are drawn to scale, with branch lengths measured in the number of substitutions per site. With light blue we depicted those samples that were considered reliable from taxonomic and technical points of view, while in orange we depicted the samples which were considered mislabelled after database query.

O. mykiss cluster, as the sequences retrieved from GenBank and BOLD. The $H$. hucho clade was formed out of other $H$. hucho sequences downloaded from GenBank and BOLD and one of our samples.

Regarding the acipenserids group, four samples of sturgeon hybrids along with six fish market samples were placed in the same $A$. ruthenus clade as the sequences from GenBank. All the samples that represented A. stellatus individuals were placed in the A. stellatus clade. None of our sequences were placed in the A. nudiventris clade, despite that the BLAST analysis gave $100 \%$ identity with $A$. nudiventris sequences from GenBank for five of our $A$. stellatus specimens. The $H$. huso clade includes, besides all of our samples labelled as $H$. huso, and the sequences retrieved from data bases designated as $H$. huso, all the best beluga sturgeon hybrid sequences, the two bester sturgeon hybrids (from aquaculture), the two sturgeon fish market samples and one GenBank sequence coming from a hybrid of (ㅇ $A$. ruthenus $\times \overbrace{}^{*} H$. dauricus). One sturgeon hybrid is also placed in the A. ruthenus clade with two other sequences. All our $A$. gueldenstaedtii samples were placed in the A. gueldenstaedtii clade. While the A. ruthenus, the A. nudiventris, the $H$. huso and the A. stellatus clades formed well-defined clades, this is not the case for the rest of the acipenserids representatives, as A. persicus, A. gueldenstaedtii, A. nacarii, A. baerii, and A. sinensis which formed mixed clades. Our $A$. baerii sequences, along with the begu sturgeon hybrid ones were placed in the clade that contained A. baerii, A. persicus and A. gueldenstaedtii.

We computed the genetic distances (Supplementary Material 3) between our COI sequences using the dist.dna function in adegenet and plotted them as histograms using all the sequences grouped based on their orders and then on their corresponding species (Fig. 3 and Supplementary Material 4). The genetic distance between the members of Salmoniformes and Acipenseriformes was 0.27 , the same as the genetic distance value obtained between Salmoniformes and Acipenseriformes without hybrids. When comparing the Acipenseriformes members between them, the genetic distance had a maximum value of 0.08 (between $A$. stellatus and both $A$. ruthenus and sterbe hybrids). In the case of Salmoniformes, the maximum value for the genetic distance $(0.2)$ was obtained for the pair T. aeliani and O. mykiss.

\section{Discussions}

The DNA barcoding technique is useful for restocking activities, when correct species assignment is crucial in order to maintain the population structure in the targeted rivers, this aspect being important not only for sturgeons, but also for salmonids. The socio-ecological importance is clear in the fish markets samples, where correct species labelling ensures not only compliance with the laws, but also a significant increase in customers' trust in the desired products.

The vast majority of the samples labelled as Salmo trutta where classified as $S$. farioides when they were compared with sequences from the databases. The phylogenetic analysis showed that proper identification of these specimens is problematic since more than one species clustered within the same group. $S$ farioides - the Adriatic brown trout (Marić and Rakočević, 2015) or Balkan brook trout (Kottelat and Freyhof, 2007) is reported to be present in the streams of the Adriatic 

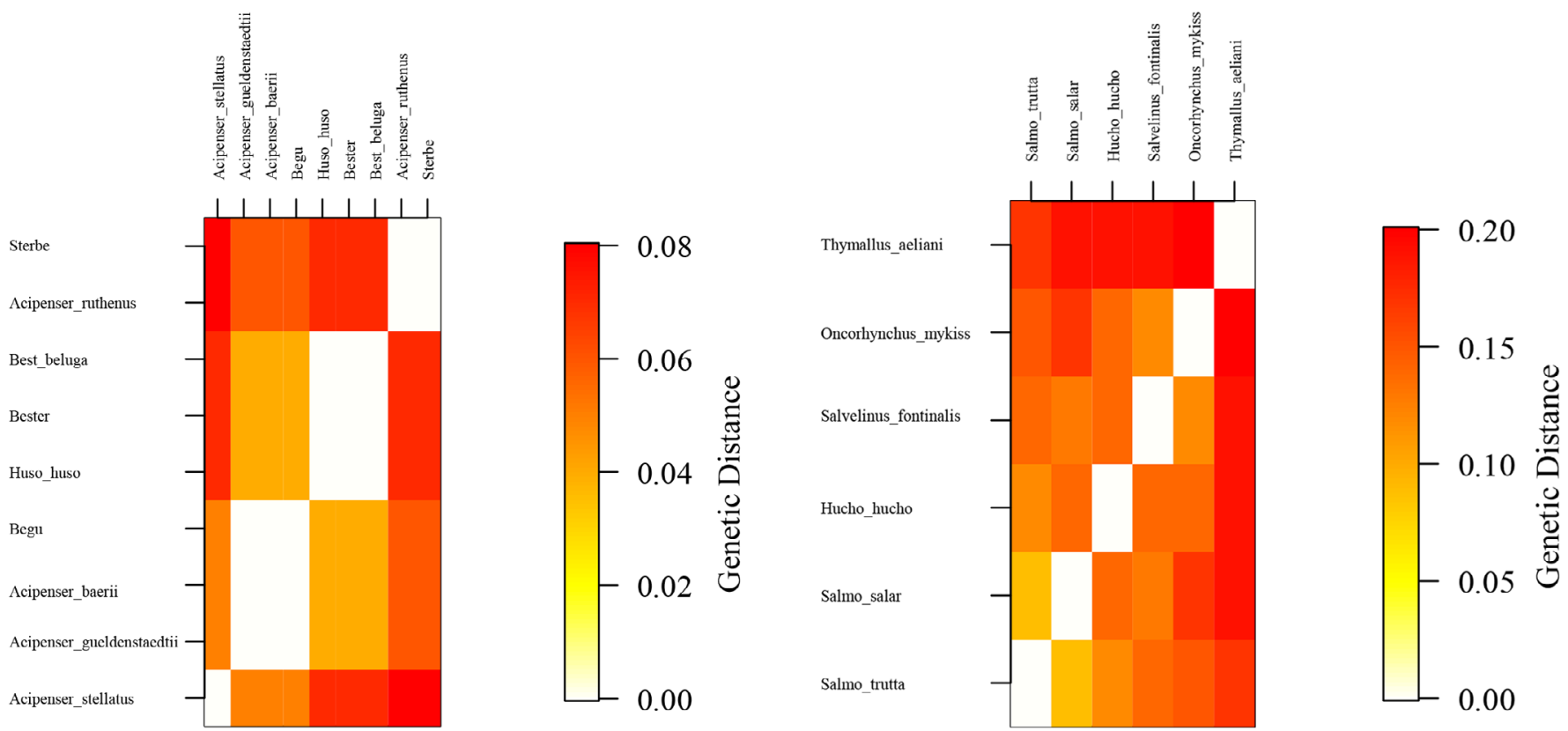

Fig. 3. Plot of the matrix pairwise genetic distances for all the Acipenseriformes species (a), all the Salmoniformes species (b). Darker colour indicates higher genetic difference between the groups.

basin, mainly in the Eastern part, in Croatia, BosniaHerzegovina, Montenegro, Albania and Greece (Kottelat and Freyhof, 2007; Marić and Rakočević, 2015), but also reported as an alien species in Serbia (Simonović et al., 2015). The identification of these samples as $S$. farioides is possibly due to the relatively short fragment of the COI gene considered as barcode - thus some polymorphic sites that could have been important for proper molecular diagnostic, might have been omitted in the PCR step. We do not exclude the possibility that the databases could be erroneous, as it was reported before (Meier et al., 2006; Collins and Cruickshank, 2012; Faisal et al., 2012; Ardura et al., 2013). Also, it is well known that brown trout shows a great eco-morphological diversity (Stelkens et al., 2012) which might lead to an erroneous morphological identification. There still are ambiguities regarding the taxonomy of salmonids, so there is possible that the barcode sequences from databases might belong to a different Salmo spp.

For one sample coming from a fish farm and labelled as $H$. hucho resulted in a $100 \%$ identity match with L. delineatus (sunbleak) in GenBank (Table 1). The sunbleak is a member of the Cyprinidae fish family, distributed in Europe and Asia, that reaches a maximum length of $9 \mathrm{~cm}$ (Kottelat, 1997), as opposed to the huchen, a salmonid that has an average length of $60-120 \mathrm{~cm}$.

Considering the phylogenetic tree topology, all of the $L$. delineatus sequences, except one, were placed in a separate clade from the salmonids. We assume that the identity assigned by the BLAST analysis is erroneous, as suggested by the placement of one sequence of $L$. delineatus in a group with $H$. hucho. This might be also the case for a sequence of $A$. nudiventris retrieved from GenBank which was actually placed in the A. stellatus group.

Another sample morphologically identified as $S$. trutta received maximum similarity and identity with $S$. labrax
(Table 1), and the phylogenetic trees support this assumption considering that $S$. labrax sequences were clustered together with various other Salmo spp. sequences. The Black Sea salmon is known to live in the rivers draining into the Black Sea, but also several rivers from Macedonia (Kottelat and Freyhof, 2007). This sample came from the Cerna River, a Danube tributary from the south-western part of Romania. Although Freyhof (2011) mentions it as a native species in Romania, S. labrax is reported to be present especially on the marine coast of the Black Sea and sporadically in the Danube River. In Romania, S. labrax is endemic and considered to be critically endangered (Oţel, 2007). In the recent years sporadic catches of individuals that morphologically have been identified as $S$. labrax have been reported in different Danube Romanian tributaries, like Bistrița Aurie River, Argeș River (Freyhof et al., 2013) and possibly Jiu River (Paraschiv and Suciu, 2016). Although, we do not exclude the possibility of catching S. labrax in the Cerna River, outside of the historical range of distribution of this species, a clear conclusion regarding the identity of our sample cannot be drawn. Unfortunately, only two sequences of S. labrax were deposited in the GenBank, this aspect hampering a more detailed analysis.

The cases of two fish market samples, which were identified as $O$. mykiss and $S$. fontinalis, but sold as $S$. trutta, along with the ones that did not have a species label, could represent a fraud attempt for the fish marketers to sell aquaculture individuals as wild ones. It is well known that fish coming from the wild has a much higher market price and that the Romanian consumers prefer wild brown trout. Both $S$. fontinalis and $O$. mykiss are rarely found in the wild in Romania and mostly in fish farms, raised especially for human consumption (Dudu et al., 2011a; Georgescu et al., 2011). Regarding the salmonids specimen identification, COI has been found useful for $S$. salar, O. mykiss, and S. fontinalis specimens. 
All the sturgeon hybrids received maximum identity and similarity scores for their maternal species. Considering the maternal inheritance of the mitochondrial genome, these specimen identifications are as expected, because each sturgeon hybrid was found in the clades of their corresponding maternal genitor species. In sturgeons the phenomenon of site heteroplasmy in mtDNA has been previously encountered (Dudu et al., 2012) due to the possible presence of paternal mtDNA along with the maternal mtDNA known as paternal leakage (Guo et al., 2006). All the COI sequences obtained here did not show this phenomenon. The DNA barcoding technique does not allow the interspecies hybrids identification and it is not useful for the molecular diagnosis of the species that easily hybridize, which is the case of sturgeons. There was no indication about the species name or about their genetic status as pure or hybrid for the sturgeon samples taken from the fish markets. For all the five specimens, the market label was sturgeon, and so we can either state that the samples are sturgeon hybrids (as it might be the case for several of our samples), or they are pure sturgeon species. Either way, all the fish markets' samples are marketed as aquaculture ones, which barcoding cannot identify as correct/accurate (Cline, 2012).

One other issue detected in sturgeons is that the barcodes of A. gueldenstaedtii, A. baerii, A. persicus, and A. naccarii, along with some of their hybrids were placed in the same monophyletic clade. A. gueldenstaedtii is a Ponto-Caspian species for which a wild population is still found in the Lower Danube. The Russian sturgeon has a high phenotypic variability; different morphs being identified. Also, this species is closely related with $A$. persicus, A. naccarii and A. baerii. Previous studies based on morphometric, meristic and genetic data have proposed the existence of cryptic lineages (pure A. gueldenstaedtii, a form A. baerii-like and a form A. naccarii-like) within the species (Birstein et al., 2005). The present study has shown the limitation of DNA barcoding when it is used to differentiate between these sturgeon species. Furthermore, for some of the salmonids and acipenserids samples, the $400+$ bp COI sequences were inadequate for accurate specimen identification. This is not a singular case since there are other studies that dealt with this problem (Birstein et al., 2009).

In order to add more accuracy to the specimen identification steps using barcoding, Rach et al. (2008) suggested DNA barcoding character-based approaches, while Ghadirnejad et al. (2009) suggested that this technique could represent a working alternative especially for identifying individuals that are part of the A. gueldenstaedtii group. Furthermore, it is known that the congeneric sturgeon species have similar morphological characteristics and most of them inhabit the same or adjacent areas (Peng et al., 2007), therefore interspecific hybridization can often occur (Ludwig et al., 2002). The morphological differentiation between pure sturgeon species and their hybrids is difficult and COI is not of much help. By combining DNA barcoding with nuclear markers analyses (Ludwig, 2006; Dudu et al., 2011b; Li et al., 2015) the rate of correct specimen identification could increase and it could be helpful to combat illegal sturgeon or caviar trade. Recently, Bayesian fingerprinting has been proposed as an alternative to DNA Barcoding technique (Yang and Rannala, 2016). This method could be applied on various types of tissues, even on fish eggs (Lewis et al., 2016).

\section{Conclusions}

This study showed that there are still some issues in identifying the correct species of the tested samples, a more accurate identification being possible at the genus level when barcoding is used as the primary identification technique. Furthermore, the barcodes have proven to be unsuccessful when used to differentiate between pure species and their hybrids and between closely related species in terms of phylogeny. This is a real problem, especially when dealing with species that have a high capacity to hybridize in the wild and in aquaculture. Also, the online databases that deal with barcodes collection are not always reliable when older entries are used as their accuracy in terms of species identification might be low.

Finally, although our results point out that the designated DNA barcodes show a low degree of interspecies variation and the classification is possible only at the genus level, this technique is still relatively cheap, fast and useful in proper identification of possibly incorrectly labelled market products. Furthermore, the food tracing and species identification programs are developing more and more each year, both in terms of technology and biological samples used for analysis.

\section{Supplementary Material}

Supplementary Material 1. List of all the sequences obtained in the laboratory. Highlighted are the sequences that were considered reliable from taxonomic and technical points of view.

Supplementary Material 2. List of sequences from GenBank and BOLD databases used for the phylogenetic analysis.

Supplementary Material 3. List of the genetic distances between and within the members of Acipenseriformes and Salmoniformes.

Supplementary Material 4. Plots with the genetic distances identified within Acipenseriformes (a) and Salmoniformes (b). Supplementary Material 5. More detailed phylogenetic trees inferred by using the Maximum Likelihood (ML) methods (a) for salmonids and (b) for acipenserids based on the Tamura 3parameter model. For the ML analysis, the tree with the highest log likelihood is shown. The trees are drawn to scale, with branch lengths measured in the number of substitutions per site. With light blue we depicted those samples that were considered reliable from taxonomic and technical points of view, while in orange we depicted the samples which were considered mislabelled after database query. The phylogenetic trees depict the position of our investigated samples among all the DNA COI sequences with maximum Identity scores in both GenBank and BOLD.

The Supplementary Material is available at https://www.alrjournal.org/10.1051/alr/2017018/olm.

Acknowledgments. This work was supported by PN-III-P2 53PTE/2016 - Technology for selection and genetic improvement in order to increase profitability of sturgeon's aquaculture, PN-III-P2 16PED/2017 - Technology for obtaining a valuable stock of huchen for growing in aquaculture and restocking and COST - CA15219 (2016-2020) - Developing new genetic tools for bioassessment of aquatic ecosystems in Europe. 


\section{References}

Ardura A, Planes S, Garcia-Vazquez G. 2013. Applications of DNA barcoding to fish landings: authentication and diversity assessment. ZooKeys 365: 49-65, doi:10.3897/zookeys.365.6409.

Bacalbasa-Dobrovici, N. 1997. Endangered migratory sturgeons of the Lower Danube River and its delta. Environ Biol Fishes 48: 201-207.

Benson D, Cavanaugh M, Clark K, et al. 2013. GenBank. Nucl Acids Res 41(Database issue): D36-D42. doi:10.1093/nar/gks1195, www.ncbi.nlm.nih.gov/genbank [Epub 2012 Nov 27, accessed on 16 July 2016].

Birstein V, Ruban G, Ludwig, A, Doukakis, P, DeSalle, R. 2005. The enigmatic Caspian Sea Russian sturgeon: how many cryptic forms does it contain? Syst Biodivers 3(2): 203-218, doi:10.1017/ S1477200005001647.

Birstein V, Desalle R, Doukakis P, Hanner R, Ruban G, Wong E. 2009. Testing taxonomic boundaries and the limit of DNA barcoding in the Siberian sturgeon, Acipenser baerii. Mitochondrial DNA 20(5-6): 110-118, doi:10.3109/19401730903168182.

Cline E. 2012. Marketplace substitution of Atlantic salmon for Pacific salmon in Washington state detected by DNA barcoding. Food Res Int 45: 388-393.

Collins R, Cruickshank R. 2012. The seven deadly sins of DNA barcoding. Mol Ecol Resour, doi:10.1111/1755-0998.12046.

Costache M, Dudu A, Georgescu SE. 2012. Low Danube sturgeon identification using DNA markers. In: Caliskan M, ed. Analysis of genetic variation in animals. InTech.

Council Regulation (EC) No 1379/2013 - accessed on 26 July 2016, http://eur-lex.europa. eu/legal-content/EN/ALL/?uri=CEL EX:32013R1379.

Darriba D, Taboada G, Doallo R, Posada D. 2012. jModelTest 2: more models, new heuristics and parallel computing. Nat Methods 9(8): 772 .

Dubey B, Meganathan PR, Haque I. 2011. DNA mini-barcoding: an approach for forensic identification of some endangered Indian snake species. Forensic Sci Int: Genet 5(3): 181-184. doi:10.1016/ j.fsigen.2010.03.001.

Dudu A, Georgescu SE, Popa O, Dinischiotu A, Costache M. 2011a. Mitochondrial $16 \mathrm{~S}$ and $12 \mathrm{~S}$ rRNA sequence analysis in four salmonid species from Romania - phylogenetic aspects. Acta Zool Acad Sci Hung 57(3): 233-246.

Dudu A, Georgescu SE, Berrebi P, Costache M. 2012. Site heteroplasmy in the mitochondrial cytochrome $\mathrm{b}$ gene of the sterlet sturgeon Acipenser ruthenus. Genet Mol Biol 35: 886-891.

Dudu A, Macarie RD, Burcea A, Georgescu SE, Costache M. 2015. Identification of Bester Hybrid and its Parental Species (o Huso huso Linnaeus, 1758 and o Acipenser ruthenus Linnaeus, 1758) by Nuclear Markers. Sci Pap: Anim Sci Biotechnol 48(1): 81-85.

Dudu A, Suciu R, Paraschiv M, Georgescu SE, Costache M, Berrebi P. 2011b. Nuclear markers of Danube sturgeons' hybridization. Int J Mol Sci 12: 6796-6809, doi:10.3390/ijms12106796.

Estoup A, Largiader C, Perrot E, Chourrot D. 1996. Rapid one-tube DNA extraction for reliable PCR detection of fish polymorphic markers and transgenes. Mol Mar Biol Biotechnol 5: 295-298.

Faisal A, Azizah S, Darlina N. 2012. Utilization of DNA barcoding for identification of fish products. In: Proceedings of the 2nd Annual International Conference, Syiah Kuala University, 2(1), pp. 55-58.

Filonzi L, Chiesa S, Vaghi M, Marzano F. 2010. Molecular barcoding reveals mislabelling of commercial fish products in Italy. Food Res Int 43: 1383-1388.
Freyhof J. 2011. Salmo labrax. The IUCN Red List of Threatened Species 2011: e.T135658A4172650, doi:10.2305/IUCN.UK. 2008.RLTS.T135658A4172650, accessed on 28 July 2016.

Freyhof J, Geiger M, Navodaru I. 2013. Short overview on Romanian ichthyofauna in 2012. In: Proceedings of the 4th Aquatic Biodiversity International Conference, p. 6.

Galimberti A, De Mattia F, Losa A, et al. 2012. DNA barcoding as a new tool for food traceability. Food Res Int 50: 55-63.

Georgescu SE, Dudu A, Suciu R, Vîrban I, Ionescu O, Costache M. 2011. Evaluarea si caracterizarea genetică a salmonidelor din România. București: Editura Universității din București, pp. 7-38.

Gessner J, Freyhof J, Kottelat M. 2010. The IUCN Red List of Threatened Species 2010, doi:10.2305/IUCN.UK. 2010-1.RLTS. T227A13039007.en - accessed on 19 July 2016.

Ghadirnejad H, Siti Azizah M, Salehi A, et al. 2009. Barcoding of five sturgeon species in Iran. J Mol Genet 1(2): 29-34.

Guindon S, Gascuel O. 2003. A simple, fast and accurate method to estimate large phylogenies by maximum-likelihood. Syst Biol 52: 696-704.

Guo X, Liu S, Liu Y. 2006. Evidence for recombination of mitochondrial DNA in triploid crucian carp. Genetics 172: $1745-1749$.

Hall T. 1999. BioEdit: a user-friendly biological sequence alignment editor and analysis program for Windows 95/98/NT. Nucl Acids Sympos Ser 41: 95-98.

Hebert P, Cywinska A, Ball SL, deWaard JR. 2003. Biological Identification through DNA barcodes. Proc R Soc 270: 313-321.

Holmes BH, Steinke D, Ward RD. 2009. Identification of shark and ray fins using DNA barcoding. Fish Res 95: 280-288.

EUNIS Species Database, http://eunis.eea.europa.eu/species/12979 accessed on 28 July 2016.

Jo H, Gim J, Jeong K, Kim H, Joo G. 2014. Application of DNA barcoding for identification of freshwater carnivorous fish diets: is number of prey items dependent on size class for Micropterus salmoides? Ecol Evol 4(2): 219-229, doi:10.1002/ece3.921.

Jombart T, Ahmed I. 2011. adegenet 1.3-1: new tools for the analysis of genome-wide SNP data. Bioinformatics. doi:10.1093/bioinfor matics/btr521.

Katoh K, Standley D. 2013. MAFFT multiple sequence alignment software version 7: improvements in performance and usability. Mol Biol Evol 30(4): 772-780, doi:10.1093/molbev/mst010.

Kimura M. 1980. A simple method for estimating evolutionary rate of base substitutions through comparative studies of nucleotide sequences. J Mol Evol 16: 111-120.

Kottelat M. 1997. European freshwater fishes. Biologia 52(Suppl. 5): $1-271$.

Kottelat M, Freyhof J. 2007. Handbook of European freshwater fishes, Publications Kottelat, Cornol, Switzerland, 646 p.

Lewis L, Richardson D, Zakharov E, Hanner R. 2016. Integrating DNA barcoding of fish eggs into ichthyoplankton monitoring programs. Fish Bull 114(2): 153-165.

Li J, Liu D, Ma Q, et al. 2015. Discriminating Dabry's sturgeon (Acipenser dabryanus) and Chinese sturgeon (A. sinensis) based on DNA barcode and six nuclear markers. Hydrobiologia 757(1): 185-196, doi:10.1007/s10750-015-2251.

Little DP. 2014. A DNA mini-barcode for land plants. Mol Ecol Resour 14(3): 437-446, doi:10.1111/1755-0998.12194.

Ludwig A. 2006. A sturgeon view on conservation genetics. Eur $J$ Wildl Res 52(1): 3-8, doi:10.1007/s10344-005-0006-2. 
Ludwig A, Debus L, Jenneckens I. 2002. A molecular approach to control the international trade in black caviar. Int Rev Hydrobiol 87: 661-673.

Ludwig A, Lieckfeldt D, Jahrl J. 2015. Mislabelled and counterfeit sturgeon caviar from Bulgaria and Romania. J Appl Ichthyol 31 (4): 587-591, doi:10.1111/jai.12856.

Marić D, Rakočević J. 2015. Some Life-History Traits of the Adriatic Brown Trout, Salmo farioides Karaman, 1938 (Salmonidae) from the Morača River (Montenegro). Acta Zool Bulg 67(2): 249-257.

Meier R, Shiyang K, Vaidya G, Ng P. 2006. DNA barcoding and taxonomy in diptera: a tale of high intraspecific variability and low identification success. Syst Biol 55(5): 715-728, doi:10.1080/ 10635150600969864.

Meusnier I, Singer GAC, Landry J, Hickey DA, Hebert PDN, Hajibabaei M. 2008. A universal DNA mini-barcode for biodiversity analysis. BMC Genomics 9(1): 214, doi:10.1186/ 1471-2164-9-214.

Miller M, Pfeiffer W, Schwartz T. 2010. Creating the CIPRES Science Gateway for inference of large phylogenetic trees. In: Proceedings of the Gateway Computing Environments Workshop (GCE), 14 November 2010, New Orleans, LA, pp. 1-8, https://www.phylo. org/ - accessed on 23 May 2016.

Oţel V. 2007. Atlasul peștilor din Rezervația Biosferei Delta Dunării. Centrul de Informare D. Dunării, 482 p.

Paraschiv M, Suciu R. 2016. Possible evidence about recruitment of Black Sea salmon (Salmo labrax Pallas, 1814) in tributaries of the Lower Danube River. In: Proceedings of The 41st International Association for Danube Research Conference, p. 25.

Paraschiv M, Suciu R, Suciu M. 2006. Present state of sturgeon stocks in the Lower Danube River, Romania. In: Proceedings of the 36th International Conference of IAD, Austrian Committee Danube Research, pp. 152-158.

Pardo M, Jimenez E, Perez-Villarreal B. 2016. Misdescription incidents in seafood sector. Food Control 62: 277-283.

Peng Z, Ludwig A, Wang D, Diogo R, Wei Q, He S. 2007. Age and biogeography of major clades in sturgeons and paddlefishes (Pisces: Acipenseriformes). Mol Phylogenet Evol 42: 854-862.

Rach J, de Salle R, Sarkar I, Schierwater B, Hadrys H. 2008. Character-based DNA barcoding allows discrimination of genera, species and populations in Odonata. Proc R Soc 275: 237-247.

Ratnasingham S, Hebert P. 2013. A DNA-based registry for all animal species: the Barcode Index Number (BIN) system. PLoS ONE 8 (8): e66213, doi:10.1371/journal.pone.0066213.

Raymakers C. 2007. CITES, the Convention on international trade in endangered species of Wild Fauna and Flora: its role in the conservation of Acipenseriformes. J Appl Ichthyol 22: 53-65.

Shokralla S, Hellberg R, Handy S, King I, Hajibabaei M. 2015. A DNA mini-barcoding system for authentication of processed fish products. Sci Rep 5: doi:10.1038/srep15894.

Simonović P, Vidović Z, Tošić A, Škraba D, Čanak-Atlagić J, Nikolić V. 2015. Risks to stocks of native trout of the Genus Salmo (Actinopterygii: Salmoniformes: Salmonidae) of Serbia and management for their recovery. Acta Ichthyol Piscat 45(2): 161-173, doi:10.3750/Aip2015.45.2.06.

Smederevac-Lalić M, Jarić I, Višnjić-Jeftić Ž, et al. 2011. Management approaches and aquaculture of sturgeons in the Lower Danube region countries. J Appl Ichthyol 27(Suppl. 3): 94-100.

Stelkens R, Jaffuel G, Escher M, Wedekind C. 2012. Genetic and phenotypic population divergence on a microgeographic scale in brown trout. Mol Ecol, doi:10.1111/j.1365-294X. 2012.05581.x.

Stoeckle M, Waggoner P, Ausubel J. 2004. Barcoding life: ten reasons. Consortium for the barcode of life (CBOL), www. barcoding.si.edu - accessed on 26 July 2016.

Tamura K. 1992. Estimation of the number of nucleotide substitutions when there are strong transition-transversion and $\mathrm{G}+\mathrm{C}$-content biases. Mol Biol Evol 9: 678-687.

Tamura K, Stecher G, Peterson D, Filipski A, Kumar S. 2013. MEGA6: Molecular Evolutionary Genetics Analysis Version 6.0. Mol Biol Evol 30: 2725-2729.

Taylor H, Harris W. 2012. An emergent science on the brink of irrelevance: a review of the past 8 years ofDNA barcoding. Mol Ecol Resour 12(3): 377-388, doi:10.1111/j.1755-0998.2012.03119.

Untergasser A, Cutcutache I, Koressaar T, et al. 2012. Primer3-new capabilities and interfaces. Nucl Acids Res 40(15): e115.

Ward R, Hanner R, Hebert P. 2009. The campaign to DNA barcode all fishes, FISH-BOL. J Fish Biol 74(2): 329-356, doi:10.1111/ j.1095-8649.2008.02080.

Ward R, Zemlak T, Innes B, Last P, Hebert P. 2005. DNA barcoding Australia's fish species. Philos Trans R Soc B 360: 1847-1857.

Yang Z, Rannala B. 2016. Species identification by Bayesian fingerprinting: a powerful alternative to DNA barcoding. bioRxiv, preprint, doi:10.1101/041608, http://www.biorxiv.org/content/bio rxiv/early/2016/02/28/041608.full.pdf.

\section{Further reading}

BLAST. www.blast.ncbi.nlm.nih.gov - accessed on 24 July 2016. BOLD. www.boldsystems.org - accessed on 24 July 2016. www.danube-sturgeons.org - accessed on 19 July 2016.

www.eurofish.dk/index.php?option $=$ com content\&view $=$ arti cle $\&$ id $=121 \% 3$ Aromania\&catid $=37 \&$ Itemid $=\overline{34}$, accessed on 13 July 2016.

www.fao.org/fi/oldsite/FCP/en/rom/profile.htm, accessed on 13 July 2016.

www.seafish.org/industry-support/legislation/traceability-and-label ling/the-fish-labelling-regulations - accessed on 16 July 2016.

www.tree.bio.ed.ac.uk/software/figtree - accessed on 25 July 2016.

Cite this article as: Popa G-O, Dudu A, Bănăduc D, Curtean-Bănăduc A, Barbălată T, Burcea A, Florescu IE(Gune), Georgescu SE, Costache M. 2017. Use of DNA barcoding in the assignment of commercially valuable fish species from Romania. Aquat. Living Resour. Vol: No 